\title{
THE PARADOX OF VOTER PARTICIPATION? A LABORATORY STUDY
}

\author{
DAVID K. LEVINE, UCLA \\ THOMAS R. PALFREY, PRINCETON UNIVERSITY
}

\begin{abstract}
It is widely believed that rational choice theory is grossly inconsistent with empirical observations about voter turnout. We report the results of an experiment designed to test the voter turnout predictions of the rational choice Palfrey-Rosenthal model of participation with asymmetric information. We find that the three main comparative statics predictions are observed in the data: the size effect, whereby turnout goes down in larger electorates; the competition effect, whereby turnout is higher in elections that are expected to be close; and the underdog effect, whereby voters supporting the less popular alternative have higher turnout rates. We also compare the quantitative magnitudes of turnout to the predictions of Nash equilibrium. We find that there is under-voting for small electorates and overvoting for large electorates, relative to Nash equilibrium. These deviations from Nash equilibrium are consistent with the logit equilibrium, which provides a good fit to the data.

Keywords: Voting, Turnout, Participation, Abstention, Experiments.

JEL Classification: A1; A2
\end{abstract}

Date: First Version: 2nd June 2004, This Version: 13th September 2005.

We thank National Science Foundation Grants SES-0314713 and SES-0079301 for financial support. We are grateful to Brian Rogers, Richard Scheelings, and Stephanie Wang for research assistance.

Corresponding Author: David K. Levine, Department of Economics, UCLA, Los Angeles, CA 90095, USA. Phone/Fax: 310-825-3810. Email: david@dklevine.com. 


\section{INTRODUCTION}

The rational choice theory of turnout, as originally formulated by Downs (1957) as a decision theory problem, and later formulated by political scientists in game theoretic terms, is perhaps the most controversial formal theory in political science. The main reason for this controversy is that in its purest instrumental form - where voting is costly, no voter obtains direct utility from the act of voting itself, and benefits are discounted by the probability of casting a pivotal vote - the basic theory grossly underpredicts turnout rates in mass elections. This should not be a huge surprise - it is probably more than mere coincidence that the act of voting is one of the least well understood phenomena in the study of politics. Why do some people vote and others not? What affects turnout rates? Indeed, differences between poll predictions and actual electoral outcomes can often be accounted for by a failure to accurately predict turnout.

This underprediction of turnout rates in mass election has been called "the paradox of voter turnout." This paradox has kindled intense debate about the value of the rational choice approach to the study of political behavior in general. Green and Shapiro (1994), in their harsh critique of rational choice theory use it as a centerpiece, and it serves as a poster boy for critics of the "homo economicus" approach to political science. Fiorina (1989), himself sympathetic to the rational choice approach, dubbed it "the paradox that ate rational choice theory."1

A variety of modifications to the basic model lead to a correction of the underprediction of turnout, but such revisions are justifiably criticized as being ad hoc and narrowly tailored to the voter turnout problem itself. There has been extensive empirical work that examines the comparative static predictions of the theory, and some that even try to estimate parametric models of the rational choice theory of turnout. But with rare exceptions, field data sets provide too little control over the distribution of voter preferences and voting costs to give much power to the tests. However, regardless of the scientific nature of these tests, in elections with over 100 million voters, the parameters required to justify turnout rates much above 0 , using a model where voting is instrumental and costly, would seem implausible to many.

What about other implications of the rational choice theory of turnout? For example, there are a number of comparative static effects. This paper focuses on three of them. First, an increase in the size of the electorate should lead to lower turnout rates. We call this the size effect. Second, turnout should be higher in elections that are expected to be closer if everyone voted. We call this the competition effect. Third, turnout among supporters of the more popular candidate or party should be less than turnout

\footnotetext{
${ }^{1}$ Grofman (1993) attributes this quote to Fiorina.
} 
among supporters of the less popular candidate. We call this the underdog effect. All three of these "comparative static" properties of the rational choice theory of turnout are stated with the usual ceteris paribus condition. That is, they are only necessarily true according to the theory if absolutely every other factor affecting turnout is held constant. That includes voter information, the distribution of voting costs, candidate quality, weather, election technology, age, income, education, voter accessibility to poll sites, and on and on. Some of these variables can and have been controlled for in empirical studies as we discuss below. It turns out that the theory is hard to reject, but this is partly due to weak tests, and the fact that all these tests are highly parametric. Consequently, the theory may fit a particular dataset well with one parametrization of the distribution of voting costs and benefits and less well under other parametric assumptions. The choice of parameter space is usually made for reasons of convenience or analytical tractability, rather than a priori theoretical reasons.

This paper takes a different approach. We use laboratory experiments to fully control for the preferences, voter information, costs, electorate size, and competitiveness. We choose a voting environment that, for very large elections, would predict very low turnout. ${ }^{2}$ While our experiments do not employ 100 million subjects, they are large by the standards of laboratory experiments - large enough for us to obtain great variation in predicted turnout rates. We have a two dimensional design of treatments that allow us to simultaneously test the size effect, the competition effect, and the underdog effect. Perhaps even more significantly, we have chosen parameters for our experimental voting environments that imply a unique quantitative prediction of the rational choice theory of turnout for each of the treatments. By varying the parameters the design enables us to see where the theory fares well and where it fares less well, both qualitatively (the comparative static predictions) and quantitatively (the exact turnout rates).

Previous papers by Schram and Sonnemans (1996), Cason and Mui (2005), and Grosser, Kugler and Schram (2005) have studied strategic voter participation in the laboratory. However, these experiments have focused on homogeneous voting costs. This implies a plethora of mixed strategy equilibria as characterized in Palfrey and Rosenthal (1983), and so makes it difficult to determine how well the theory performs. In the field of course, voter participation costs are heterogeneous. Here we study a model with

\footnotetext{
${ }^{2}$ Asymptotically, turnout for our parametrization is $2 \%$. Previous voter turnout experiments have explored environments where theoretical turnout is always large, regardless of the number of voters. Not surprisingly, they observe high turnout rates. We choose a parametrization that leads to relatively rapidly declining turnout for two reasons: first, it enables us to test that turnout declines as the theory predicts. Second, if we allowed many voters with negative costs, we would have many fewer useful observations.
} 
heterogeneous and privately known participation costs, as in Palfrey and Rosenthal (1985). This leads to strong predictions, as the Nash equilibrium under our parameters is unique. We find in the laboratory that the theory performs remarkably well at the aggregate level, predicting participation rates and comparative statics well, and doing a good job predicting participation even in relatively large elections, with only moderate amounts of overparticipation. At the individual level, the model fares less well, as individual behavior is too noisy to be consistent with Nash equilibrium. A quantal response equilibrium model based on stochastic choice, on the other hand, does somewhat better in the aggregate, while accounting much better for individual behavior. One feature of strategic voting that deserves emphasis is that the types of individual errors predicted by quantal response equilibrium have relative little impact on aggregate participation rates - this "robustness" appears to be a key feature of strategic models of voter turnout.

\section{THE MODEL}

The experiments are based on the Palfrey and Rosenthal (1985) model of turnout when voters have privately known voting costs. There are $N$ voters, divided into two groups, the supporters of candidate A and the supporters of candidate B. In Palfrey and Rosenthal, it was assumed that the two groups were equal in size, but here we consider the minor extension where the size of group A is $N_{A}$ and the size of group B is $N_{B}$, and $N_{A}<N_{B}$. The two sizes are assumed to be common knowledge to all voters. We will refer to group A as the minority group and group B as the majority group. We will refer to candidate $\mathrm{A}$ as the underdog and candidate $\mathrm{B}$ as the frontrunner. The voting rule is simple plurality. Voters decide simultaneously whether to cast a vote for their preferred candidate or to abstain. Whichever candidate receives more votes wins the election, with ties broken randomly. If candidate A wins then all members of group A receive a reward of $H$ and all members of group B receive a reward of $L<H$. If candidate B wins then all members of group B receive a reward of $H$ and all members of group A receive a reward of $L<H$. These reward are common knowledge. Voting is costly, and the voting cost to voter $i$ is denoted $c_{i}$. Voter $i$ knows $c_{i}$ before deciding whether to vote or abstain, but the distribution from which the voting costs of other voters are drawn - each voter's cost is an independent draw from the same distribution. The density function of the cost distribution, $f(c)$, exists and is common knowledge and assumed to be positive everywhere on the support.

A quasi-symmetric equilibrium of the voting game is a pair of turnout strategies, $\left(\tau_{A}, \tau_{B}\right)$, where $\tau_{A}$ specifies the probability a member of group 
A votes, as a function of his or her voting cost. The assumption of quasisymmetry is that all members of the same group use the same strategy. It is straightforward to prove existence of a quasi-symmetric equilibrium in cutpoint strategies. Moreover, all equilibria must use cutpoint strategies, which greatly simplifies the analysis. A cutpoint strategy for voter $i$ specifies a critical cost level, $c_{i}^{*}$ with the property that voter $i$ abstains if and only if $c_{i}>c_{i}^{*}$. Hence, a quasi-symmetric equilibrium is given by a pair of numbers $\left(c_{A}^{*}, c_{B}^{*}\right)$ corresponding to the cutpoint used by members of group $\mathrm{A}$ and group $\mathrm{B}$, respectively. A quasi symmetric equilibrium implies an aggregate voting probability for each group, $\left(p_{A}^{*}, p_{B}^{*}\right)$, given by:

$$
\begin{aligned}
& p_{A}^{*}=\int_{-\infty}^{\infty} \tau(c) f(c) d c=\int_{-\infty}^{c_{A}^{*}} f(c) d c=F\left(c_{A}^{*}\right) \\
& p_{B}^{*}=\int_{-\infty}^{\infty} \tau_{B}(c) f(c) d c=\int_{-\infty}^{c_{B}^{*}} f(c) d c=F\left(c_{B}^{*}\right)
\end{aligned}
$$

In order for $\left(c_{A}^{*}, c_{B}^{*}\right)$ to be an equilibrium, all voters must be optimizing, and this condition boils down to requiring that a voter with a cost equal to the cutpoint is exactly indifferent between voting and abstaining. This indifference reduces to:

$$
\begin{aligned}
c_{A}^{*} & =\frac{H-L}{2} \pi_{A}^{*} \\
c_{B}^{*} & =\frac{H-L}{2} \pi_{B}^{*}
\end{aligned}
$$

where $\pi_{j}^{*}$ is the probability that a vote by a member of group $j$ will be pivotal (make or break a tie), given the equilibrium voting strategies of all other members of both groups. Since a voter will create a tie if and only if the number of other members voting in his own group is exactly one less than the number of members voting in the other group, and will break a tie if and only if these two numbers are equal. The probability of these events depends only $p_{A}^{*}, p_{B}^{*}, N_{A}$ and $N_{B}$ and is calculated easily using binomial 
formulas.

$$
\begin{gathered}
\pi_{A}^{*}=\sum_{k=0}^{N_{A}-1}\left(\frac{N_{A}-1}{k}\right)\left(\frac{N_{B}}{k}\right)\left(p_{A}^{*}\right)^{k}\left(1-p_{A}^{*}\right)^{N_{A}-1-k}\left(p_{B}^{*}\right)^{k}\left(1-p_{B}^{*}\right)^{N_{B}-k}+ \\
\sum_{k=0}^{N_{A}-1}\left(\frac{N_{A}-1}{k}\right)\left(\frac{N_{B}}{k+1}\right)\left(p_{A}^{*}\right)^{k}\left(1-p_{A}^{*}\right)^{N_{A}-1-k}\left(p_{B}^{*}\right)^{k+1}\left(1-p_{B}^{*}\right)^{N_{B}-1-k}
\end{gathered}
$$

$$
\begin{gathered}
\pi_{B}^{*}=\sum_{k=0}^{N_{A}}\left(\frac{N_{A}}{k}\right)\left(\frac{N_{B}-1}{k}\right)\left(p_{A}^{*}\right)^{k}\left(1-p_{A}^{*}\right)^{N_{A}-k}\left(p_{B}^{*}\right)^{k}\left(1-p_{B}^{*}\right)^{N_{B}-1-k}+ \\
\sum_{k=1}^{N_{A}}\left(\frac{N_{A}}{k}\right)\left(\frac{N_{B}}{k-1}\right)\left(p_{A}^{*}\right)^{k}\left(1-p_{A}^{*}\right)^{N_{A}-k}\left(p_{B}^{*}\right)^{k-1}\left(1-p_{B}^{*}\right)^{N_{B}-k}
\end{gathered}
$$

\section{The EXPERIMENTAl Design AND Hypotheses}

The experiment was designed with many features in mind, both from a logistical standpoint of experimental methodology, and from a parametric standpoint of choosing the specific parametric treatments. The primary treatment variable in the experiment was the choice of parameters for the game. After normalizing the payoffs $(L$ and $H$ ), the game described in the previous section is fully characterized by $N_{A}, N_{B}$, and $f$. Since the three central hypotheses are the size effect, the underdog effect, and the competition effect, we were able to test all three by fixing $f$ throughout the experiment, and varying only $N_{A}$ and $N_{B}$. The payoffs were $L=5$ and $H=105$. We conducted elections with $N \in\{3,9,27,51\}$. For each of these electorate sizes, we have two subtreatments, ${ }^{3}$ one where $N_{B}=2 N_{A}$ and one where $N_{B}=N_{A}+1$. We refer to the former as the landslide treatment and the latter as the toss-up treatment. This modified $4 \times 2$ design is given in Table 1.

\footnotetext{
${ }^{3}$ When $N=3$ these two treatments collapse into one treatment.
} 
TABLE 1. Experimental Design

\begin{tabular}{|c|c|c|c|c|c|c|}
\hline$N$ & $N_{A}$ & $N_{B}$ & \#subjects & \#sessions & \#elections & \# obs \\
\hline 3 & 1 & 2 & 51 & 4 & 850 & 2550 \\
\hline 9 & 3 & 6 & 81 & 9 & 450 & 4050 \\
\hline 9 & 4 & 5 & 81 & 9 & 450 & 4050 \\
\hline 27 & 9 & 18 & 108 & 4 & 200 & 5400 \\
\hline 27 & 13 & 14 & 108 & 4 & 200 & 5400 \\
\hline 51 & 17 & 34 & 102 & 2 & 100 & 5100 \\
\hline 51 & 25 & 24 & 102 & 2 & 100 & 5100 \\
\hline
\end{tabular}

Our choice of the cost distribution, $f$, was dictated by two considerations, one theoretical and one logistical. Theoretically, there can be multiple quasi-symmetric equilibria for some cost distributions and some values of $N_{A}$ and $N_{B}$. We needed to find a distribution that had a unique equilibrium for all of our different $\left(N_{A}, N_{B}\right)$ treatments, and one that was also easy to explain to naive subjects. A uniform distribution of voting costs ranging from 0 to 55 satisfies both of these desiderata. Since the payoff for making or breaking a tie is 50 , voters who draw costs greater than 50 have a strict dominant strategy to abstain and voters with costs equal to 50 have a weakly dominant strategy to abstain. Equilibrium is unique for all our treatments, and the uniform distribution can be explained in terms of all costs within a give range being equally likely. The unique Nash equilibrium turnout probabilities for the two groups are given in Table 2.

There were six main logistical challenges to conducting our experiment. First, we wanted a design that would be easy to explain to naive subjects who know nothing about the model and may be completely unfamiliar with abstract mathematical concepts such as probability distributions. Second, we wanted to control the information flows so that individuals in the experiment would know their own costs but only the distribution of costs for the other individuals. Third, we wanted the parameters of the model and the voting rule to be as close to common knowledge as possible. Fourth, we wanted subjects to have an opportunity to gain experience, since past experiments have shown that behavior in games with pure strategy equilibria shows systematic convergence of behavior with experience. Fifth, we wanted a context-free design so that uncontrollable individual factors would not add another source of noise or introduce alternative explanations for the results. Sixth, we wanted a design which allowed within subject tests of the hypothesized effects, as well as between subject tests.

Our design generates a number of comparative statics hypotheses. These are listed below, with an explanation of each: 


\section{Hypotheses}

For our hypotheses, we use the following notation. We denote the turnout probability for the underdog as a function of the sizes of group $A$ and group $B$ is by $p_{A}^{*}\left(N_{A}, N_{B}\right)$ and the probability for the frontrunner by $p_{A}^{*}\left(N_{A}, N_{B}\right)$.

\section{Comparative Statics Hypotheses}

H1. : The Size Effect. Holding the relative size of the two groups constant, turnout in each party is decreasing in $N$. Formally, this implies 42 specific hypotheses in the form of pairwise inequalities. Two examples are $p_{A}^{*}(4,5)>p_{A}^{*}(13,14)$ and $p_{B}^{*}(1,2)>p_{B}^{*}(17,34)$. Generally these inequalities take the form that if $N<M$, then $p_{j}^{*}\left(\frac{N-1}{2}, \frac{N+1}{2}\right)>$ $p_{j}^{*}\left(\frac{M+1}{2}, \frac{M+1}{2}\right)$ and $p_{j}^{*}\left(\frac{N}{3}, \frac{2 N}{3}\right)>p_{j}^{*}\left(\frac{M}{3}, \frac{2 M}{3}\right)$ for $j=A, B$. In addition, there is the weaker hypothesis that total turnout is decreasing in $N$.

H2. : The Competition Effect. Holding the total size of the electorate constant, turnout in each party is decreasing in $N_{A}-N_{B}$. This gives us 6 specific hypotheses in the form of pairwise inequalities. They are $p_{A}^{*}(4,5)>p_{A}^{*}(3,6), p_{A}^{*}(13,14)>p_{A}^{*}(9,18), p_{A}^{*}(25,26)>$ $p_{A}^{*}(17,34), p_{B}^{*}(4,5)>p_{B}^{*}(3,6), p_{B}^{*}(13,14)>p_{B}^{*}(9,18), p_{B}^{*}(25,26)>$ $p_{B}^{*}(17,34)$. Note that this hypothesis does not apply for the $N=3$ treatment, since $\frac{N-1}{2}=\frac{N}{3}$ in that case.

H3. : The Underdog Effect. For $N>3$, turnout of party $A$ is greater than turnout of party $B$. This gives us 6 specific hypotheses in the form of pairwise inequalities. They are $p_{A}^{*}(4,5)>p_{B}^{*}(4,5)$, $p_{A}^{*}(3,6)>p_{B}^{*}(3,6), p_{A}^{*}(13,14)>p_{B}^{*}(13,14), p_{A}^{*}(9,18)>p_{B}^{*}(9,18)$, $p_{A}^{*}(25,26)>p_{B}^{*}(25,26), p_{A}^{*}(17,34)>p_{B}^{*}(17,34)$.

H4. : Counter-example to the Underdog Effect. For $N=3$, turnout of party $A$ is less than turnout of party $B$. Specifically, $p_{A}^{*}(1,2)<$ $p_{B}^{*}(1,2)$.

In addition to these comparative statics hypotheses, there are the specific quantitative hypotheses about turnout, given in Table 2. There are two additional sets of hypotheses about aggregate outcomes, listed in the last two columns of that table. The first is the equilibrium probability of a pivotal outcome. A pivotal outcome is one in which at least one voter is pivotal. That is, the outcome is either a tie or one vote away from a tie. It is noteworthy that if at least one voter is pivotal, then usually many voters are pivotal. In fact, in the case the vote is exactly a tie, all voters in both parties are pivotal, in the sense that if any single voter had voted differently, the tie would be broken. 
TABLE 2. Nash Equilibrium Predictions

\begin{tabular}{|c|c|c|c|c|c|c|}
\hline$N$ & $N_{A}$ & $N_{B}$ & $p_{A}^{*}$ & $p_{B}^{*}$ & $\pi^{*}$ & $Q^{*}$ \\
\hline 3 & 1 & 2 & .537 & .640 & .810 & .070 \\
\hline 9 & 3 & 6 & .413 & .375 & .599 & .151 \\
\hline 9 & 4 & 5 & .460 & .452 & .666 & .270 \\
\hline 27 & 9 & 18 & .270 & .228 & .409 & .187 \\
\hline 27 & 13 & 14 & .302 & .297 & .466 & .418 \\
\hline 51 & 17 & 34 & .206 & .171 & .309 & .153 \\
\hline 51 & 25 & 26 & .238 & .235 & .375 & .435 \\
\hline
\end{tabular}

It is straightforward to show that the comparative statics for the probability of a pivotal outcome are ordered exactly the same as the equilibrium turnout rates. This is true because in equilibrium the cutpoint for each party is proportional to the probability of making or breaking a tie. We denote this equilibrium probability $\pi^{*}\left(N_{A}, N_{B}\right)$. This generates a parallel set of hypotheses to $H 1-H 2$, which we call $H 5$ and $H 6$ and these parallel hypotheses are tested by looking at frequencies of pivotal events rather than turnout rates. The exact quantitative pivot probabilities are given in Table 2.

H5 : The size effect on the frequency of Pivotal Events. Holding the relative size of the two groups constant, the frequency of pivotal events is decreasing in $N$. Formally, this implies 21 specific hypotheses in the form of pairwise inequalities. An example is $\pi^{*}(4,5)>\pi^{*}(13,14)$. Generally these inequalities take the form that if $N<M$, then $\pi^{*}\left(\frac{N-1}{2}, \frac{N+1}{2}\right)>\pi^{*}\left(\frac{M+1}{2}, \frac{M+1}{2}\right)$ and $\pi^{*}\left(\frac{N}{3}, \frac{2 N}{3}\right)>$ $\pi^{*}\left(\frac{M}{3}, \frac{2 M}{3}\right)$.

H6 : The competition effect on the frequency of Pivotal Events. Holding the total size of the electorate constant, the frequency of pivotal events is decreasing in $N_{A}-N_{B}$. This gives us 3 specific hypotheses in the form of pairwise inequalities: $\pi^{*}(4,5)>\pi^{*}(3,6)$; $\pi^{*}(13,14)>\pi^{*}(9,18) ; \pi^{*}(25,26)>\pi^{*}(17,34)$.

Finally, there is a separate set of hypotheses about the probability of an upset. We define an upset as an outcome of the election where the underdog ties or receives more votes than the frontrunner. These upset probabilities are higher in toss-up races than in landslide races, but do not vary much with $N$. We denote the equilibrium upset probability by $Q^{*}\left(N_{A}, N_{B}\right)$, and the theoretical values for each treatment are in Table 2 . This upset hypotheses are stated formally below: 
H7 : Upset Rates. The underdog is more likely to tie or win in tossup races than in landslide races, and these upset probabilities are decreasing in $N$. This generates 15 specific hypotheses in the form of pairwise inequalities. Twelve of these hypotheses are of the form $Q^{*}\left(\frac{N-1}{2}, \frac{N+1}{2}\right)>Q^{*}\left(\frac{M+1}{2}, \frac{M+1}{2}\right)$ and $Q^{*}\left(\frac{N}{3}, \frac{2 N}{3}\right)>Q^{*}\left(\frac{M}{3}, \frac{2 M}{3}\right)$ for $N<M$. The other three hypotheses are $Q^{*}\left(\frac{N-1}{2}, \frac{N+1}{2}\right)>Q^{*}\left(\frac{N}{3}, \frac{2 N}{3}\right)$, $N=9,27,54$.

In addition to hypotheses about aggregate behavior, the unique Bayesian Nash equilibrium also makes very sharp predictions about individual behavior. Specifically, all individuals should be using exact cutpoint rules. Moreover, these cutpoint rules should be precisely those corresponding to the turnout rates listed in Table 2. Obviously, hypotheses as sharp as this will inevitably be rejected. The cutpoint rules are pure strategies, so a single violation of the exact cutpoint rule by any subject in will completely reject the theory. Accordingly, we will pursue these hypotheses in the results section more descriptively, rather than formally testing them. We will however, consider a bounded rationality model in which subjects follow a cutpoint rule stochastically - that is, they follow it most of the time, but violate it some of the time. This allows us to classify subjects according to their propensity to vote, which we expect to vary due to many diverse factors such as expectations about pivotal events, risk aversion, attitudes about group norms, social preferences, judgement fallacies and so forth.

There are also qualitative hypotheses that can be addressed at the individual level. In our design, subjects were in only one electorate size $(3,9$, 27 , or 51), but participated in a multiple elections, both toss-up and landslide, and participated as members of both the small group and the large group. This is explained in more detail in the next session. Accordingly, we address $H 2, H 3$, and $H 4$ at the individual level as well as at the aggregate level.

\section{EXPERIMENTAL PROTOCOL}

Subjects were recruited by email announcement from a subject pool consisting of registered UCLA students. A total of 284 different subjects participated in the study. We conduced 20 separate sessions using networked computers at the CASSEL experimental facility. ${ }^{4}$ In each session, $N$ was held fixed throughout the entire session. For the $N>3$ sessions, there were two subsessions of 50 rounds each; one subsession was the toss-up treatment and the other subsession was the landslide treatment. The sequencing

\footnotetext{
${ }^{4}$ The software was programmed as server/client applications in Java, using the open source experimental software package called Multistage (http://multistage.ssel.caltech.edu/).
} 
of the two treatments was done both ways for each $N$. Before each round, each subject was assigned to either group $A$ or group $B$ and assigned a voting cost, drawn independently from the uniform distribution between 0 and 55 , in integer increments. 5 Therefore, each subject gained experience as a member of the majority and minority party for exactly one value of $N$, and participated in both 50 landslide and 50 toss-up elections. Instructions were read aloud so everyone could hear, and Powerpoint slides were projected in front of the room to help explain the rules and to make all the common knowledge to the extent possible. After the instructions were read, subjects were walked through two practice rounds with randomly forced choices and then were required to correctly answer all the questions on a computerized comprehension quiz before the experiment began. After the first 50 rounds, a very short set of new instructions were read aloud, explaining that the sizes of group $A$ and group $B$ would be different for the next 50 rounds.

The wording in the instructions was written so as to induce as neutral an environment as possible. 6 There was no mention of voting or winning or losing or costs. The labels were abstract. The smaller groups was referred to the alpha group $(A)$ and the larger group was referred to as the beta group $(B)$. Individuals were asked in each round to choose $\mathrm{X}$ or $\mathrm{Y}$. If more members of $A(B)$ chose $\mathrm{X}$ than members of $B(A)$ chose $\mathrm{X}$, then each member of $A(B)$ received 105 and each member of group $B(A)$ received 5 . In case of a tie, each member of each group received 55 (the expected value of a fair coin toss). Therefore, voting corresponded to "choosing X" and abstaining corresponded to "choosing Y." The voting cost was referred to as a "Y bonus," and was added to a player's earnings if that player chose $\mathrm{Y}$ instead of $\mathrm{X}$ in an election. Therefore, the voting cost was implemented as an opportunity cost. If a player chose $X$, that player did not receive their $\mathrm{Y}$ bonus for that election. Bonuses were randomly redrawn in every round, independently for each subject, and subjects were only told their own Y bonus. 7

The $N=3$ sessions were conducted slightly differently. First, there were only 50 rounds, since the toss-up and landslide treatments were identical. Second, the sessions were conducted with either 12 or 15 subjects, who were randomly rematched each round into subgroups of 3 each period, before being assigned a party and a voting cost. This allowed us to obtain a

\footnotetext{
${ }^{5}$ Every 100 points paid off $\$ .37$.

${ }^{6}$ A sample of the instructions from one of the 27 person sessions is in the Appendix.

${ }^{7}$ We ran two additional sessions with $n=9$ where the instructions were presented in the context of voting decision in elections, and the two groups were referred to as parties. The results were nearly identical and are discussed briefly in the results section.
} 
comparable number of subjects for the $N=3$ treatment as the other treatments.

\section{RESUlTS}

5.1. Aggregate results. The analysis of results at the aggregate level is carried out at three levels. First, we look at the empirical turnout rates, and how they vary with respect electorate size, the competitiveness of the election, and whether voters are from the majority or minority parties. This enables us to address hypotheses $H 1-H 4$. Next, we focus on outcomes, and show how the empirical frequencies of pivotal events and upsets vary with electorate size and electoral competitiveness.

5.1.1. Turnout Rates. Table 3 displays the observed turnout rates for each party and each treatment, denoted $\widehat{p}$ with standard errors in parenthesis, alongside the Nash equilibrium values. ${ }^{8}$ Out of 42 pairwise comparisons of turnout rates, 40 have the same sign as predicted by the theory.

TABLE 3. Turnout Rates - Comparison of Theory and Data

\begin{tabular}{|c|c|c|c|c|c|c|c|c|}
\hline$N$ & $N_{A}$ & $N_{B}$ & $\widehat{p}_{A}$ & $p_{A}^{\text {Nash }}$ & $p_{A}^{\lambda=7}$ & $\widehat{p}_{B}$ & $p_{B}^{\text {Nash }}$ & $p_{B}^{\lambda=7}$ \\
\hline 3 & 1 & 2 & $.530(.017)$ & .537 & .549 & $.593(.012)$ & .640 & .616 \\
\hline 9 & 3 & 6 & $.436(.013)$ & .413 & .421 & $.398(.009)$ & .374 & .395 \\
\hline 9 & 4 & 5 & $.479(.012)$ & .460 & .468 & $.451(.010)$ & .452 & .463 \\
\hline 27 & 9 & 18 & $.377(.011)$ & .270 & .297 & $.282(.007)$ & .228 & .275 \\
\hline 27 & 13 & 14 & $.385(.009)$ & .302 & .348 & $.356(.009)$ & .297 & .345 \\
\hline 51 & 17 & 34 & $.333(.011)$ & .206 & .245 & $.266(.008)$ & .171 & .230 \\
\hline 51 & 25 & 26 & $.390(.010)$ & .238 & .301 & $.362(.009)$ & .235 & .300 \\
\hline
\end{tabular}

Figure 1 graphs the observed and predicted turnout rates for all the various treatments and both parties. The dotted lines represent the actual data. The dashed lines are the Nash equilibrium turnout rates. The solid lines correspond to the quantal response equilibrium turnout rates, and are explained later. The left side graphs show the majority turnout rates as a function of electorate size; the right hand side graphs show minority turnout rates.

\footnotetext{
${ }^{8}$ The standard errors assume independence of the observations. Since there is dependence due to multiple observations of the same individual, these should be interpreted as a lower bound on the standard errors. We take a second look at this by examining individual effects in the next section.
} 
FIgURE 5.1. Minority and Majority Party Turnout Rates As Function of Electorate Size
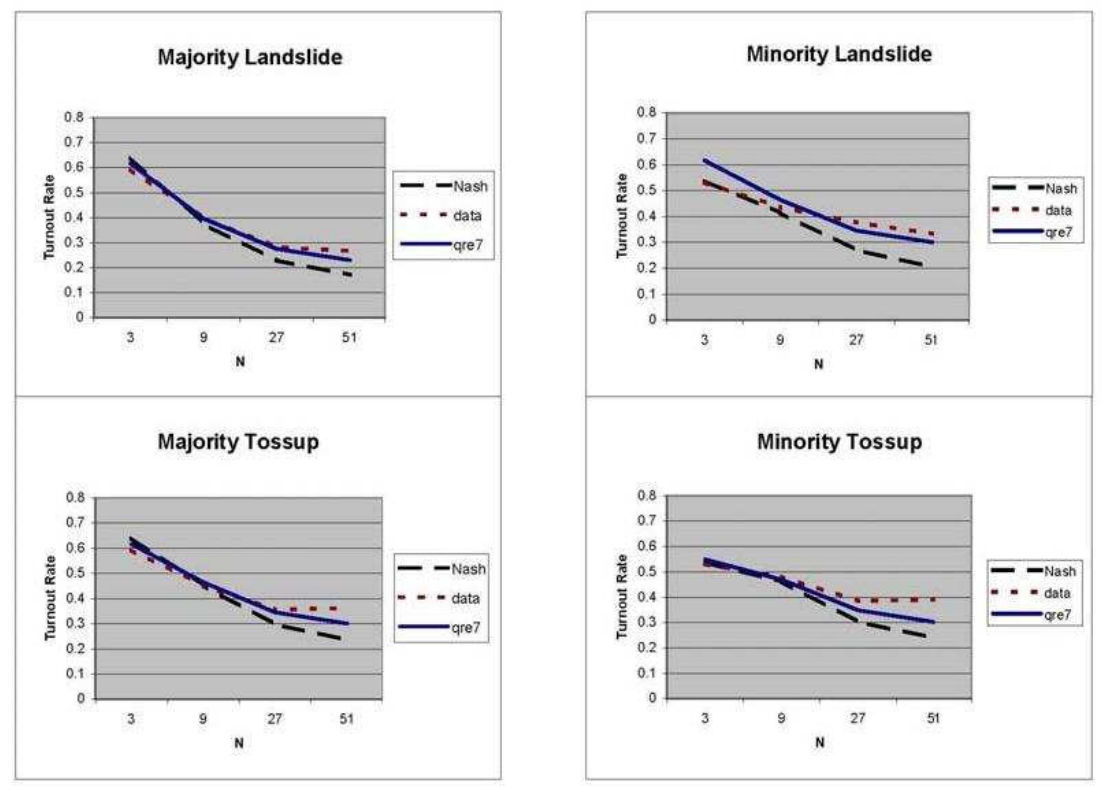

Hypotheses about the competition effect $(H 2)$, the underdog effect $(H 3)$, and the 3 -voter counterexample to the underdog effect $(H 4)$, are supported without exception. That is, all pairwise comparisons of turnout rates for those hypotheses are the same as predicted by the theory. Particularly noteworthy (and surprising to us), is the support for $H 4$ : the minority turns out less than the majority in only one instance, which is precisely the one predicted by the theory $\left(N_{A}=1, N_{B}=2\right)$. In all other cases, there is greater turnout by the minority party.

The size effect, $H 1$, is supported with the exception of the comparison of turnout in tossup races with 27 versus 51 voters. In that comparison, both the minority and majority parties vote slightly more often in the 51 case than the 27 case, but these are both quantitatively smaller than all other differences (.005 and .006, respectively), and neither is large relative to sampling variation as measured by the standard errors.

Quantitatively, the turnout rates we observe for the smallest electorate $(\mathrm{N}=3)$, are significantly lower than predicted by theory, turnout rates for somewhat larger electorates $(\mathrm{N}=9)$ are approximately equal to the Nash equilibrium value, while turnout rates for the largest electorates $(\mathrm{N}=27,51)$ 
are higher than predicted by theory. ${ }^{9}$ As a general rule, we find that turnout rates are closer to .5 than theory predicts. This mirrors findings by Goeree and Holt (2005) for a broad class of games with a similar structure to our voter turnout experiments. 10

We conducted two additional sessions with $N=9$, as a robustness check for the abstract context. In these session, we changed the terminology of "X" and "Y" to "Vote" and "Abstain." Each round was referred to as an election, groups were called parties, and so forth. The turnout rates are given in Table 4, side by side with the results from sessions run with an abstract protocol, with standard errors in parenthesis. Three differences are positive and one is negative. All are small in magnitude, and are small compared to the sampling variation in the Election Context Protocol estimates as measured by the standard errors.

TABLE 4. Comparison of Turnout Rates Across Protocols $N=9$

\begin{tabular}{|c|c|c|}
\hline & Abstract Protocol & Election Context Protocol \\
\hline$\widehat{p}_{A}$ tossup & $479(.012)$ & $0.475(.022)$ \\
\hline$\widehat{p}_{B}$ tossup & $.451(.010)$ & $0.480(.018)$ \\
\hline$\widehat{p}_{A}$ landslide & $.436(.013)$ & $0.460(.025)$ \\
\hline$\widehat{p}_{B}$ landslide & $.398(.0094)$ & $0.400(.018)$ \\
\hline
\end{tabular}

We also report the results of a simple probit regression of the probability a voter turns out as a function of which party the voter was in (majority or minority), whether the or not the race was a toss-up, and the size of the electorate. The results are given below in Table 5, along with T-statistics. The coefficients on all three variables are highly significant, and have the predicted signs: negative effect of majority party membership; positive effect of toss-up; and negative effect of electorate size.

TABle 5. Probit Regression of Turnout on Treatment Variables

\begin{tabular}{|c|c|}
\hline Dep = vote & coefficient (standard error) \\
\hline constant & $-.035(.018)$ \\
\hline$N$ & $-.0088(.0004)$ \\
\hline tossup & $.10(.015)$ \\
\hline majority party & $-.113(.015)$ \\
\hline
\end{tabular}

\footnotetext{
${ }^{9}$ An exception is majority party turnout in the $n=9$ tossup races, where turnout is less than the Nash equilibrium (but not statistically significant).

${ }^{10}$ They study binary choice games such as threshold public goods games, where observed contribution rates tend to exceed the equilibrium predictions when the equilibrium is below .5 , and are too low when the equilibrium is above .5 percent.
} 
Because the observed turnout frequencies in the sessions with $\mathrm{N}=3,27,51$ were significantly different from the Nash equilibrium turnout rates, we also included a variable for experience, which takes on values from 1 to 50, corresponding to the round number. Recall that each treatment in each session lasted for 50 rounds. We hypothesis that behavior should converge in the direction of Nash equilibrium, a phenomenon that has been widely observed in game theory experiments. However, the effect of experience should be different depending on $\mathrm{N}$. For $\mathrm{N}=9$, aggregate turnout rates are almost exactly equal to Nash prediction, so we do not expect experience to change behavior. For $\mathrm{N}=3$, observed turnout is too low, so convergence in the direction of equilibrium implies that the sign of the experience coefficient should be positive. The opposite should be true for $\mathrm{N}=27$ and $\mathrm{N}=51$, since observed turnout is too high. Because the expected effects differ across $\mathrm{N}$, we estimate the effect separately for each $\mathrm{N}$.

The results are given in Table 6, and provide some support for the idea that behavior is adjusting in the direction of equilibrium. For both the $\mathrm{N}=27$ and the $\mathrm{N}=51$ sessions, the coefficient on experience is precisely estimated and negative. In both cases, there was approximately a 5 percentage point drop in turnout between the first and last rounds, controlling for party and tossup. For the $\mathrm{N}=3$ sessions, the coefficient is positive, as predicted, but there is insufficient data to distinguish is clearly from zero. For $\mathrm{N}=9$, the coefficient is virtually equal to zero, as expected.

TABLE 6. Probit Regression of Turnout by Size of Electorate

\begin{tabular}{|c|c|c|c|c|}
\hline Dep=Vote & \multicolumn{4}{|c|}{$\mathrm{N}$} \\
\hline & 3 & 9 & 27 & 51 \\
\hline constant & $.058(.053)$ & $-.15(.042)$ & $-.31(.033)$ & $-.41(.034)$ \\
\hline tossup & - & $.094(.032)$ & $.13(.025)$ & $.22(.026)$ \\
\hline majority party & $.088(.053)$ & $-.079(.033)$ & $.16(.025)$ & $-.13(.026)$ \\
\hline experience & $.0016(.0017)$ & $-.0002(.001)$ & $-.0028(.0009)$ & $-.0025(.0009)$ \\
\hline
\end{tabular}

5.1.2. Upsets and Pivotal Events. Table 6 displays the observed and equilibrium frequencies of pivotal events, $\pi$, for each treatment and the observed and equilibrium upset rates, $Q$. Standard errors are reported in parentheses. 
TABle 7. Pivotal Events and Upset Rates. Comparison of Theory and Data

\begin{tabular}{|c|c|c|c|c|c|c|c|}
\hline$N$ & $N_{A}$ & $N_{B}$ & $\pi^{*}$ & $\widehat{p}$ & $Q^{*}$ & $\widehat{Q}$ & \#elections \\
\hline 3 & 1 & 2 & .810 & $.846(.007)$ & .070 & $.092(.006)$ & 850 \\
\hline 9 & 3 & 6 & .599 & $.580(.008)$ & .151 & $.146(.005)$ & 450 \\
\hline 9 & 4 & 5 & .666 & $.697(.007)$ & .270 & $.280(.007)$ & 450 \\
\hline 27 & 9 & 18 & .409 & $.395(.007)$ & .187 & $.165(.005)$ & 200 \\
\hline 27 & 13 & 14 & .466 & $.440(.007)$ & .418 & $.435(.007)$ & 200 \\
\hline 51 & 17 & 34 & .309 & $.260(.006)$ & .153 & $.170(.005)$ & 100 \\
\hline 51 & 25 & 26 & .375 & $.390(.007)$ & .435 & $.440(.007)$ & 100 \\
\hline
\end{tabular}

Overall, the data provide strong support for hypotheses $H 5, H 6$, and $H 7$. Every single one of the 21 size effect inequalities for pivotal events $(H 5)$ are observed in the data, and all three of the competition effect inequalities for pivotal events $(\mathrm{H} 6)$ are also found. The same is true for the 15 predicted inequalities for upsets $(H 7)$, with only one exception: $\widehat{Q}(9,18)<\widehat{Q}(17,34)$, but the difference is only 0.005 .

Also noteworthy is the fact that the data tracks the theory very closely quantitatively, as well as qualitatively. Indeed the quantitative departures from theory are behaviorally meaningless. To illustrate this, figure 2 graphs the observed and predicted values of $\pi$ and $Q$ for all treatments. A simple linear regression of observed on theoretical rates, using all 14 data points in the figure (including both pivot probabilities and upsets) produces an intercept equal to-0.01, a slope equal to 1.03 and an $R^{2}=.99$.

Figure 5.2. Pivotal Events and Upsets

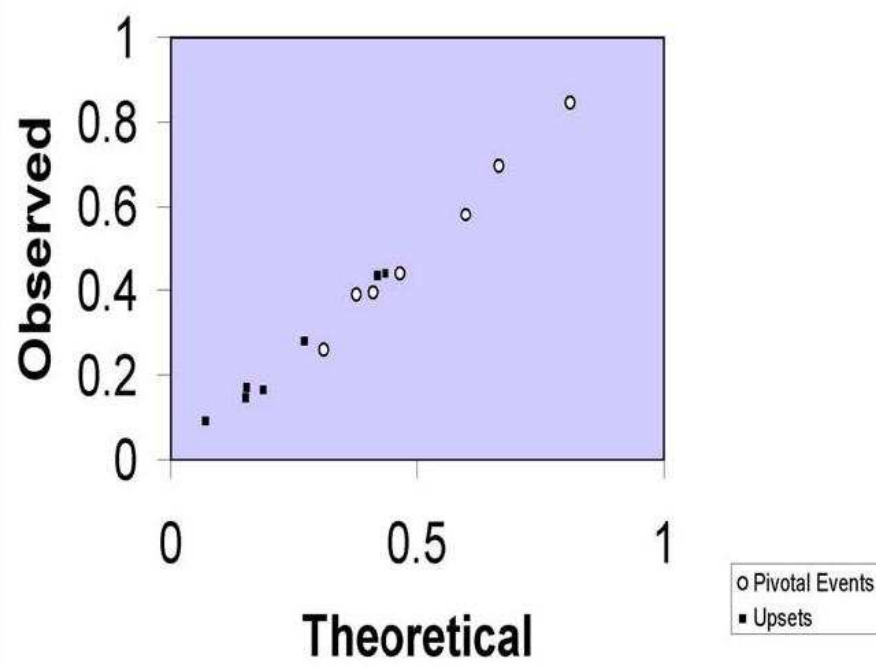


5.2. Quantal Response Equilibrium turnout rates. In this voter participation game, subjects with cutpoints close to the equilibrium cutpoint are nearly indifferent between voting and abstaining. Consequently, very small errors in their judgment about the pivot probabilities, or other factors, could lead them to make a suboptimal decision. With this in mind, it makes sense to explore models such errors are possible and where the probability of such errors are derived endogenously in the model.

One alternative is to allow a small amount of bounded rationality and assume that players are not optimizing but instead choose according to a Logit stochastic choice rule. If they also have rational expectations, then it is called the Logit quantal response equilibrium model. In a quantal response equilibrium, decision making no longer follows a deterministic cutpoint rule. Rather, a voter's turnout probability is a continuous strictly increasing function of voting cost, $\tau(\cdot)$, which is equal to .5 precisely at the voting cost at which the voter is exactly indifferent between voting and abstaining. If $\pi_{j}$ is the probability of a voter in party $j$ is pivotal (which will generally be different for minority and majority voters), then in a logit equilibrium such a voter's turnout probability, if his voting $\operatorname{cost}$ is $c$ follows the formula:

$$
\tau_{j}(c ; \lambda)=\frac{1}{1+e^{\lambda\left(c-\pi_{j}\right)}}
$$

where $\lambda$ is the logit response parameter. Integrating over all possible voting costs, we obtain the voter's ex ante turnout probability:

$$
p_{j}^{*}(\lambda)=\int_{-\infty}^{\infty} \tau_{j}(c ; \lambda) f(c) d c
$$

There will be one such equation for each party, analogous to equations 1 and 2 in the Nash equilibrium analysis. 11

Since this is an equilibrium model, $\pi_{j}$ is determined endogenously, and will depend on $\lambda$, since it depends on $p_{j}^{*}$, which depends on $\tau_{j}$, which in turn depends on $\lambda$. The equilibrium pivot probabilities, $\left\{\pi_{A}(\lambda), \pi_{B}(\lambda)\right\}$, are then computed using formulas similar to equations 3 and 4 .

The logit response parameter, $\lambda$ is a free parameter corresponding to the slope of the logit response curve. We estimate this free parameter to obtain a fit of the data to the logit QRE model. To avoid overfitting, we constrain $\lambda$ to be the same in all treatments. This is a straightforward estimation exercise. Using the data, it is easy to compute the maximum likelihood estimate of $\lambda$ based on the pooled data from all treatments. We do this by actually computing the logit equilibrium of each game for a grid of values of $\lambda$, and then can directly construct the likelihood function of our pooled

\footnotetext{
${ }^{11}$ The Nash equilibrium analysis is equivalent to the limiting case of $\lambda=\infty$.
} 
data, as a function of $\lambda$. This yields a maximum likelihood estimate equal to $\widehat{\lambda}=7$.

We then use that estimated value, $\widehat{\lambda}=7$, along with the actual draws of voting costs, to compute for each treatment and each part, theoretical QRE turnout rates, denoted $p^{\lambda=7}$. These are given in two columns of Table 3, and also displayed in Figure 1. Two observations are clear. First, the QRE model fits the data better. Second, the QRE model provides exactly the right qualitative correction to the Nash model. Recall that the Nash model underpredicted turnout in larger elections and overpredicted turnout in small elections, and did fairly well for intermediate-sized elections. The QRE predicts less turnout than Nash equilibrium in the smallest election, and more turnout than Nash equilibrium in the large elections. QRE also predicts even greater amounts of overvoting (relative to Nash), as the size of the election becomes larger and larger, which is what we observed in the data.

As an alternative way to see how well the logit choice model is capturing voter behavior, Figure 5.3 graphs turnout rates by "normalized" voting cost. For each treatment and each party, we define a normalized voting cost as the difference between a voter's actual voting cost and the logit equilibrium cutpoint (for $\lambda=7$ ). Thus, for example, if the QRE cutpoint for an A voter in some treatment were, say, 15 , and their actual cost were 25 , their normalized voting cost would be 10 . Thus our normalization allows us to display all the voting behavior in a single graph. According to the logit QRE, the voting probabilities should follow a logit curve, which is the smooth decreasing curve in the figure (for $\lambda=7$ ). The decreasing step-function curve averages the data across normalized cost intervals of .03. 
FIGURE 5.3. Turnout Rates as Function of Cost, Compared to Logit Response with $\lambda=7$

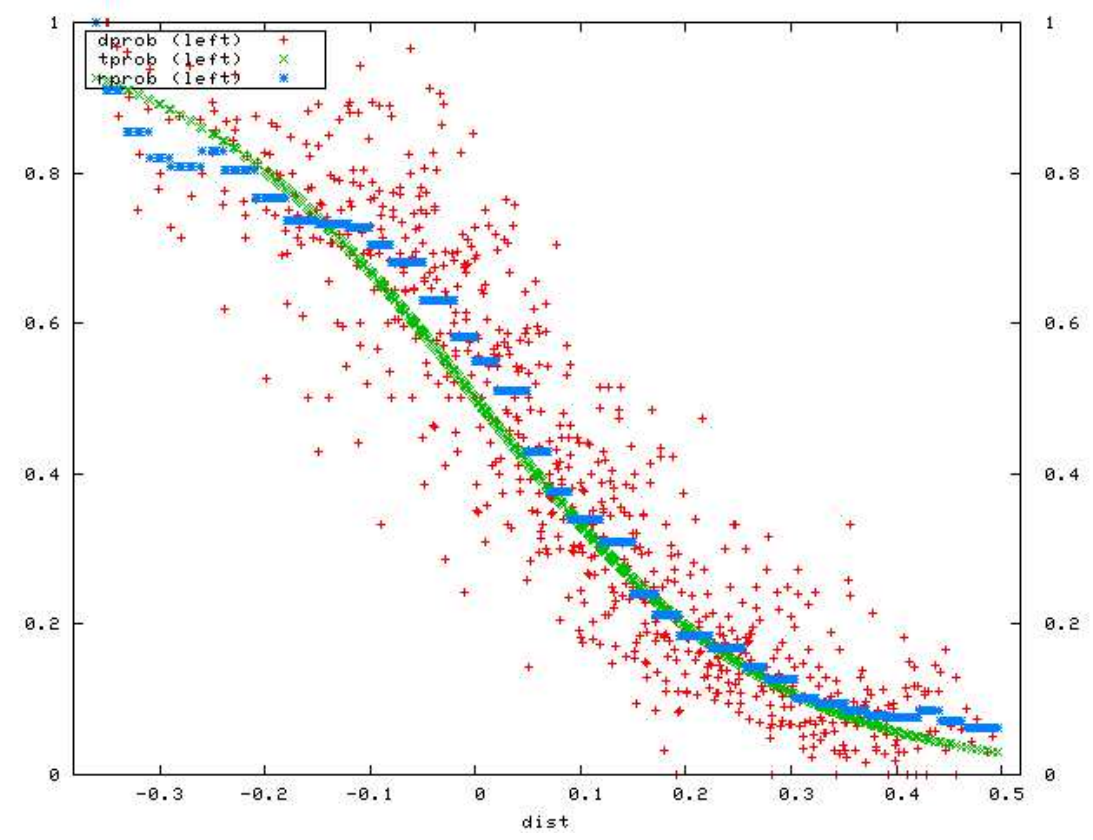

5.3. Individual Results. We turn now from examining the aggregate implications of the theory to implications for individual behavior. Nash equilibrium predicts that all subjects should follow a common cutpoint rule that is, the smooth logit curve in Figure 5.3 should be a vertical line at zero. In fact, as that graph shows, individual behavior shows substantially more variation than Nash equilibrium allows, heterogeneity that is well accounted for by the additional QRE parameter. We now look at more detail at the play of specific subjects.

5.3.1. Estimating Individual Cutpoints. To summarize the behavior of individual subjects, we assume that each subject is following a cutpoint rule and attempt to estimate subject by subject what that rule is. Recall that best responses always take the form of cutoff rules, whereby a voter should vote if and only if the cost they draw is greater than or equal to a critical cost level, $c$.

For each treatment and each subject, we estimated cutpoint rules in the following simple way. For each subject $i$ and treatment $j$, we have $K_{i j}$ observations of cost, decision pairs $\left(c_{t}, d_{t}\right)$. Fix a cutpoint $0 \leq c_{i j} \leq 55$. If for observation $t$ in this sample of $K_{i j}$ observations we have

(1) $c_{t}<c_{i j}$ and $d_{t}=$ vote or if

(2) $c_{t}>c_{i j}$ and $d_{t}=$ abstain or if 
(3) $c_{t}=c_{i j}$

we say that observation $t$ is consistent with the cutpoint $c_{i j}$. Otherwise, we say that observation $t$ is an error with respect to the cutpoint $c_{i j} .12$ The estimated cutpoint, $\widehat{c}_{i j}$ is the cutpoint that one that minimizes the number of errors 13

Using this procedure, we can produce a distribution of cutpoints for each treatment and a distribution of error rates for each treatment. Figures 5.4 and 5.5 show the cumulative distribution of cutpoints for all of the treatments.

\footnotetext{
${ }^{12}$ Alternatively, one could discount the error by how close the cost is to the cutpoint. This could be done for example by estimating for each $i j$ pair a logit choice function and defining the estimated cutpoint as the point at which the estimated logit choice probability is exactly .5.

${ }^{13}$ In case there are multiple error-minimizing cutpoints, we use the average of them.
} 
FIGURE 5.4. Landslide Cumulative Distributions of Cutpoints

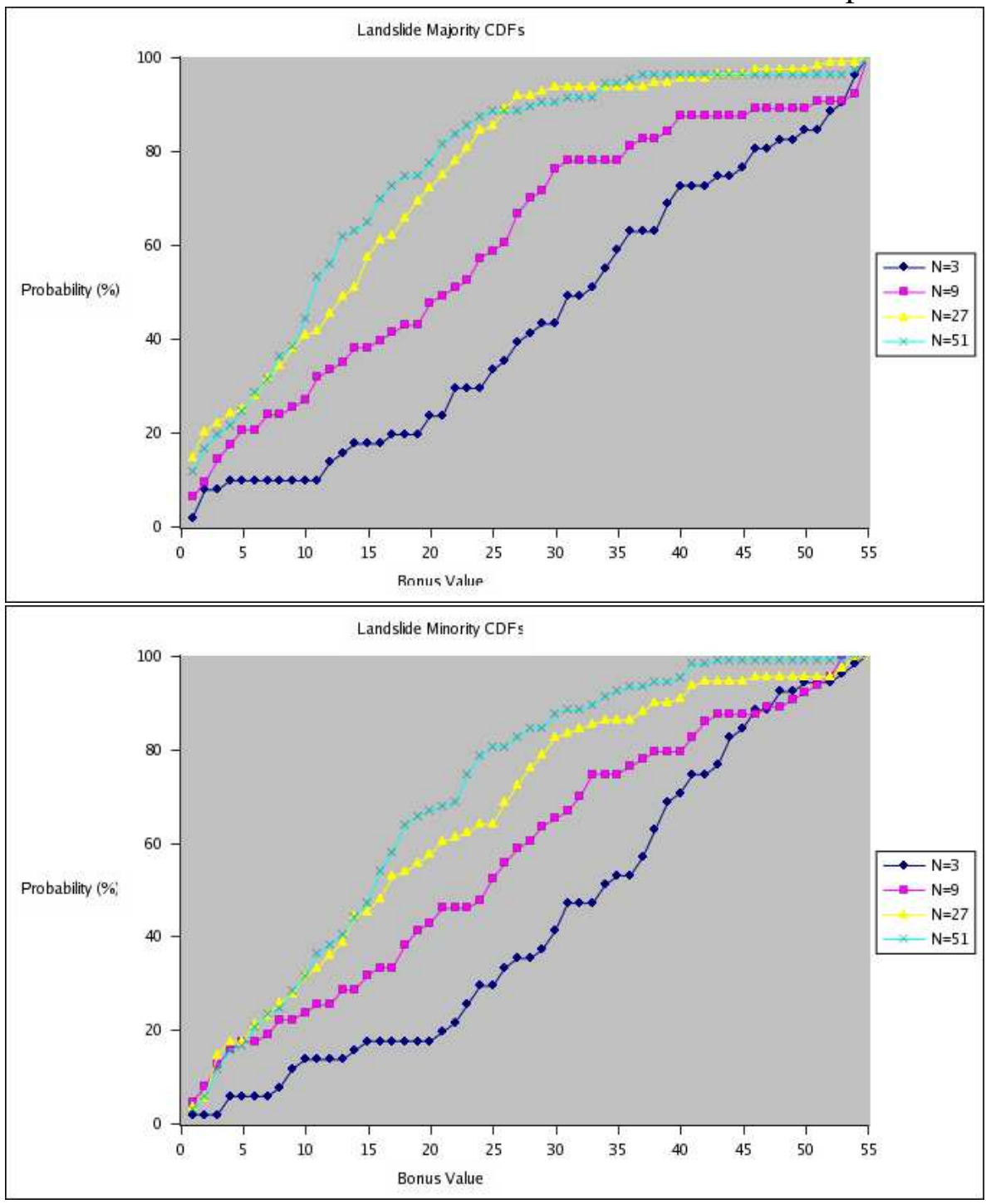


FIGURE 5.5. Tossup Cumulative Distribution of Cutpoints

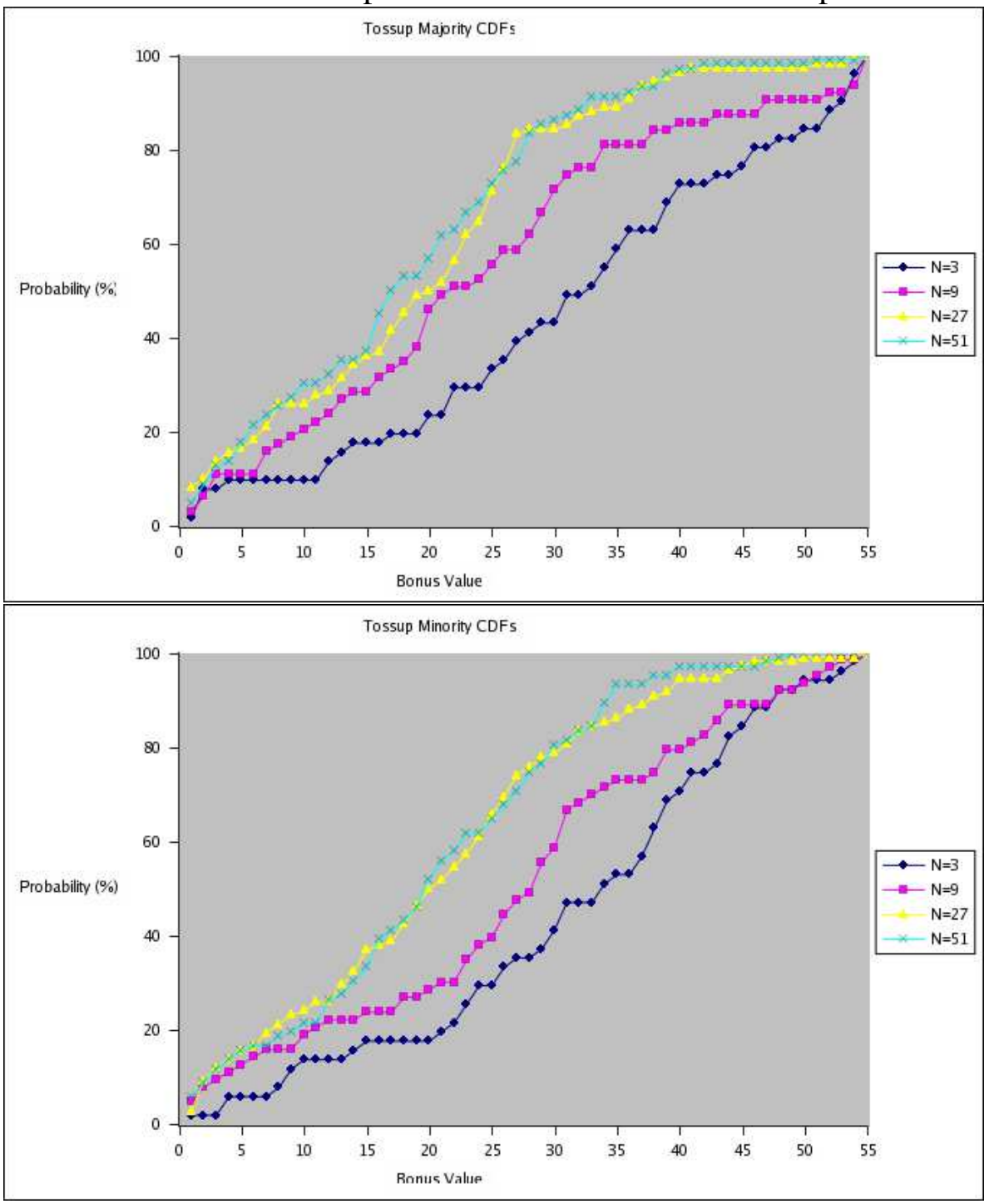

The density for error rates is shown in Figure 5.6. As can be seen, there are errors, but in general not so many, indicating that to a reasonable approximation individuals followed consistent cutpoint rules. 
FIGURE 5.6. Cutpoint Error Density

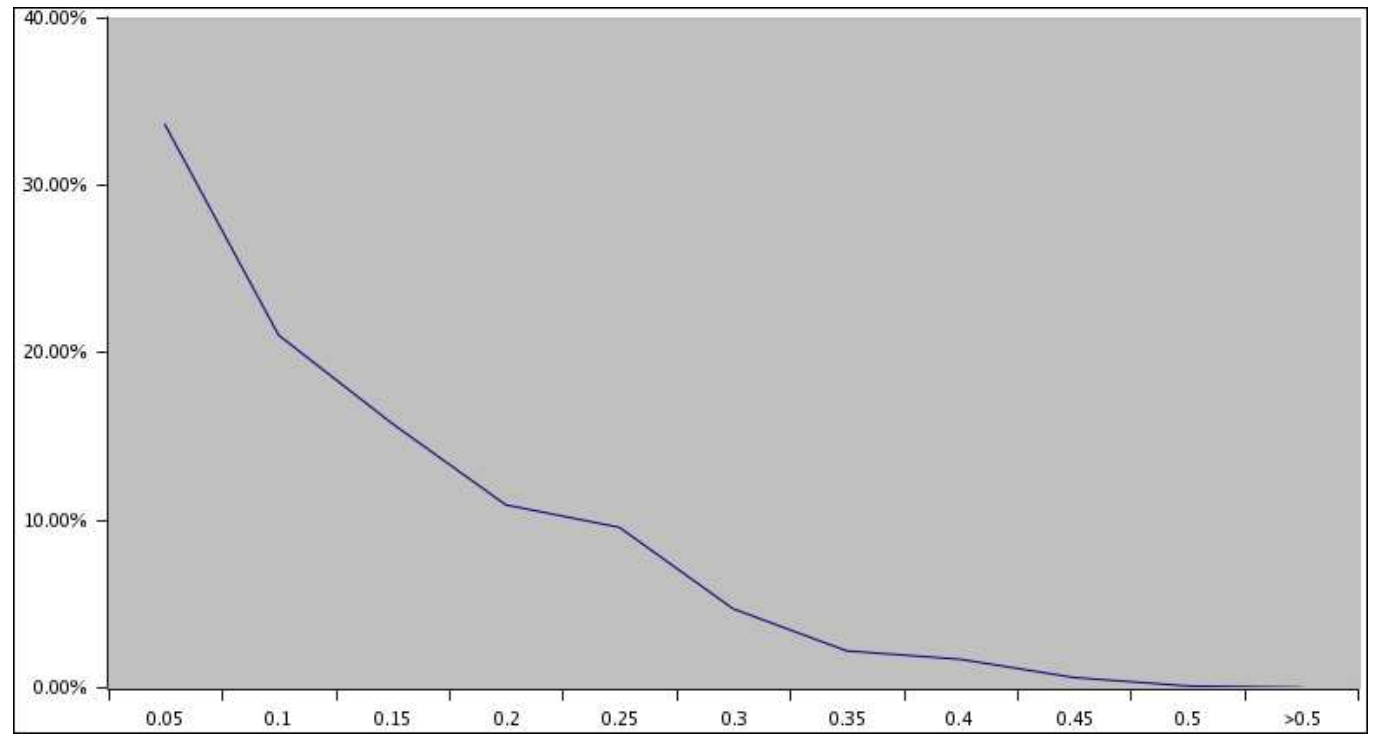

5.3.2. Toss-ups and Landslides. We turn now to comparative statics at the individual level. For the experiments with $N>3$, we have four paired observations for individuals: holding fixed whether the individual is in the minority or majority, we can consider the difference in their cutpoint between a tossup and a landslide; holding fixed whether the election is a tossup or a landslide, we can consider the difference in their cutpoint between being in the minority and the majority. According to the theory - either Nash or QRE - all of these differences should be positive. Table 8 reports the fraction of these differences that are positive. As can be seen, this is always above $50 \%$ 
and generally $60 \%$ or higher. This is reinforced by Table 9 which reports the average size of these differences. These numbers are all positive.

TABLE 8. Fraction of Positive Paired Differences

\begin{tabular}{|c|c|c|c|c|}
\hline & Minority & Majority & Tossup & Landslide \\
\hline$N$ & Tossup-Landslide & Tossup-Landslide & Minority-Majority & Minority-Majority \\
\hline 51 & 0.60 & 0.75 & 0.52 & 0.65 \\
\hline 27 & 0.56 & 0.68 & 0.56 & 0.68 \\
\hline 9 & 0.56 & 0.60 & 0.62 & 0.56 \\
\hline 3 & & & 0.57 & \\
\hline
\end{tabular}

TABlE 9. Average Size of Paired Differences

\begin{tabular}{|c|c|c|c|c|}
\hline & Minority & Majority & Tossup & Landslide \\
\hline$N$ & Tossup-Landslide & Tossup-Landslide & Minority-Majority & Minority-Majority \\
\hline 51 & 3.2 & 4.4 & 1.8 & 3.1 \\
\hline 27 & 1.1 & 4.6 & 1.2 & 4.7 \\
\hline 9 & 2.6 & 1.7 & 2.7 & 1.8 \\
\hline 3 & & & 0.10 & \\
\hline
\end{tabular}

\section{CONCLUSIONS}

There are six main findings from this voter turnout experiment.

First, and most important, all of the comparative statics from the standard Bayesian Nash equilibrium model of instrumental strategic voting were strongly supported by the data. We find strong evidence for the size effect, the competition effect, and the underdog effect. The evidence is based on turnout rates, frequency of pivotal events, and upset probabilities. It is further supported by individual level analysis that was possible because of the experiment's mixed within/across subject design, which allows us to compare an individual subject's decisions in multiple treatments.

Second, voters are highly responsive to voting cost, with turnout rates declining sharply with the cost of voting. As a first approximation, most voters use cutpoint strategies, as predicted by the theory.

Third, a close look at individual behavior reveals that few voters use exact deterministic cutpoint strategies; choice behavior appears to have a stochastic element. This replicates a finding from several other studies of games with binary choices and continuous types, where best response rules are cutpoint strategies. 14

\footnotetext{
${ }^{14}$ See, for example, Casella, Gelman, and Palfrey (2005), Palfrey and Prisbrey (1997), and Palfrey and Rosenthal (1991).
} 
Fourth, voters were less responsive to changes in the parameters of the environment than the equilibrium. In particular, this resulted in turnout rates that were too low for $N=3$ and that exceeded the Nash equilibrium rates for the larger groups, with overvoting especially noticeable in the $N=51$ treatment.

Fifth, an equilibrium approach based on the logit version of QRE, which incorporates the kind of stochastic choice observed at the individual level, provides a significant improvement in fit over the Nash model, as well as providing an explanation for undervoting (relative to Nash) in small elections and overvoting in large elections. Furthermore, the responsiveness of participation rates to voting costs is tracked very closely by a logit curve (Figure 3). Nonetheless, the logit QRE model may not fully account for the magnitude of overvoting in the largest elections of our sample, unless there are higher error rates (smaller $\lambda$ ) in larger elections, a possibility which does not have an obvious rationale a priori.

Sixth, the experiment was conducted in a neutral abstract context with no mention of voting, or winning, or parties or elections. In the two extra sessions conducted specifically in a voting context, subject behavior was the same as the abstract context. Hence the phenomena we observe apparently are not limited to elections, but are more general. In particular the observation of overvoting relative to the equilibrium cannot be easily dismissed by appealing to arguments such as citizen duty, high school civics classes, or fear that one's spouse of workmates will castigate one for not voting.

The challenge now is to come up with an explanation of over voting that is not specific to elections, but applies more broadly to participation games in general. The one alternative explored here, QRE, provides a partial explanation, but undershoots the overvoting in large elections. Another explanation we have considered, that voters systematically overestimate the probability of being pivotal, is directly contradicted by the $N=3$ data, where we observe overvoting. For the same reason, our data also contradicts group-specific altruism models, and also the group-utilitarian approach of Harsanyi (1980), recently proposed as an explanation of high voter turnout by Feddersen and Sandroni (2002).

Another alternative model minimax regret, is due to Ferejohn and Fiorina. That model is easily rejected, because it implies that turnout should independent the probability of being decisive, which contradicts the size effect, the competition effect, and the underdog effect.

We conjecture that some kind of mixture of models such as these, that would include a variety of behavioral types, will ultimately be needed for a more complete explanation of this phenomenon. One framework for building and estimating such models has been developed by El-Gamal and 
Grether (1995), and such an approach may be worth exploring here. However, developing a specification of types for the voting context that is not simply ad hoc would be a challenge, and the actual computation and estimation of such a model may be difficult.

In conclusion, the strength of the comparative statics results should not be understated. The fact that the experiment clearly supports the three main equilibrium comparative static effects (size, competition, and underdog) in participation games, and the finding that voters use approximate cutpoint strategies, demonstrates that voting behavior is highly strategic, with voters responding to both the cost of voting and the probability of being pivotal. 


\section{REFERENCES}

[1] Casella, A., A. Gelman, and T. Palfrey. 2005. "An Experimental Study of Storable Votes." Games and Economic Behavior. Forthcoming.

[2] Cason, T. and V.-L. Mui, 2005. "Uncertainty and resistance to reform in laboratory participation games. "European Journal of Political Economy. forthcoming

[3] Coate, Stephen and M. Conlin. 2005. "A Group Rule-Utilitarian Approach to Voter Turnout: Theory and Evidence." American Economic Review. Forthcoming.

[4] Downs, A. 1957. An Economic Theory of Democracy. New York: Harper and Row.

[5] El-Gamal, M. and D. Grether. "Are People Bayesian? Uncovering Behavioral Strategies." Journal of the American Statistical Association. 90, 1137-45.

[6] Grosser, Jens, T. Kugler, and A. Schram. 2004. "Preference Uncertainty and Voter Participation: An Experimental Study." Working Paper. University of Amsterdam.

[7] Feddersen, T. and A. Sandroni (2002), "A Theory of Participation in Elections with Ethical Voters." Working Paper. Northwestern University.

[8] Goeree, J, and C. Holt. 2005. "An Explanation of Anomalous Behavior in Models of Political Participation" American Political Science Review.

[9] Green, D. and I. Shapiro. 1994. Pathologies of Rational Choice Theory. New Haven: Yale University Press.

[10] Grofman, B. 1993. "Is Turnout the Paradox that Ate Rational Choice Theory?" in Information, Participation, and Choice. ed. B. Grofman. University of Michigan Press: Ann Arbor.

[11] Grosser, J., T. Kugler and A. Schram. 2005. "Preference Uncertainty, Voter Participation and Electoral Efficiency: An Experimental Study." mimeo Cologne.

[12] Hansen, S., T. Palfrey, and H. Rosenthal. 1987. "The Downsian Model of Electoral Participation: Formal Theory and Empirical Analysis of the Constituency Size Effect." Public Choice. 52: 15-33.

[13] Harsanyi, J. (1980). "Rule Utilitarianism, Rights, Obligations, and the Theory of Rational Behavior." Theory and Decision. 12: 115-33.

[14] Palfrey, T. and J. Prisbrey. 1997. "Anomalous Behavior in Linear Public Goods Experiments: How Much and Why?" American Economic Review. 87, 829-46.

[15] Palfrey, T. and H. Rosenthal. 1983. "A Strategic Calculus of Voting." Public Choice.

[16] Palfrey, T. and H. Rosenthal. 1985. "Voter Participation and Strategic Uncertainty." American Political Science Review. 79: 62-78.

[17] Palfrey, T. and H. Rosenthal. 1991. "Testing Game-Theoretic Models of Free Riding: New Evidence on Probability Bias and Learning," in Laboratory Research in Political Economy (T. Palfrey, ed.), University of Michigan Press:Ann Arbor.

[18] Schram, A. and J. Sonnemans (1991), "Why people vote: Free riding and the production and consumption of social pressure," Journal of Economic Psychology 12, 575-620.

[19] Schram, A. and J. Sonnemans (1996), "Why people vote: Experimental evidence," Journal of Economic Psychology 17, 417-442.

[20] Schram, A. and J. Sonnemans (1996), "Voter Turnout as a Participation Game: An Experimental Investigation,” International Journal of Game Theory 25, 385-406. 


\section{APPENDIX}

Sample instructions from a 9 person session (abstract protocol)

Thank you for agreeing to participate in this research experiment on group decision making. During the experiment we require your complete, undistracted attention. So we ask that you follow instructions carefully. Please do not open other applications on your computer, chat with other students, read books or do homework.

For your participation, you will be paid in cash, at the end of the experiment. Different participants may earn different amounts. What you earn depends partly on your decisions, partly on the decisions of others, and partly on chance. So it is important that you listen carefully, and fully understand the instructions before we begin. There will be a short comprehension quiz after the upcoming practice round, which you all need to pass before we can begin the paid sessions.

The entire experiment will take place through computer terminals, and all interaction between you will take place through the computers. It is important that you not talk or in any way try to communicate with other participants during the experiments, except according to the rules described in the instructions.

We will start with a brief instruction period. During the instruction period, you will be given a complete description of the experiment and will be shown how to use the computers. If you have any questions during the instruction period, raise your hand and your question will be answered out loud so everyone can hear. If any difficulties arise after the experiment has begun, raise your hand, and an experimenter will come and assist you privately.

Please open your envelope and remove the Record Sheet. Do not lose this Record Sheet, as you will need the sheet throughout the experiment to record your earnings.

This experiment will begin with two brief practice sessions to help familiarize you with the rules. The practice session will be followed by 2 different paid sessions. Each paid session will consist of 50 rounds.

At the end of the last paid session, you will be paid the sum of what you have earned in the two paid sessions, plus the show-up fee of \$5.00. Everyone will be paid in private and you are under no obligation to tell others how much you earned. Your earnings during the experiment are denominated in POINTS. Your DOLLAR earnings are determined by multiplying 
your earnings in POINTS by a conversion rate. In this experiment, the conversion rate is 0.0037 , meaning that 100 POINTS is worth 37 cents.

There are 9 participants in today's experiment. You will participate in 2 brief practice sessions and then 2 paid sessions of 50 rounds each.

Please turn your attention to the screen at the front of the room. We will demonstrate how the rounds are played.

\section{SCREEN 1 (menu)}

Everyone should have a screen like the screen projected on stage. If you have something different from what is projected on stage, please raise your hand and the staff will assist you.

[CHECK TO SEE IF ANYONE RAISES THEIR HAND]

Please do not begin unless we tell you to do so. Please have your attention focused on the stage during this demonstration period. Please click on the MENU icon. This will bring up screen 2 showing the icons underneath.

SCREEN 2 (icons)

On this second screen click on the MULTISTAGE CLIENT icon. A pop up window will appear right in front of you.

SCREEN 3 (client information)

Enter your first and last name in the box that appears and then click submit. You will then see screen 4

SCREEN 4 (initializing)

Once everyone has logged in, you will be randomly assigned to one of two groups the ALPHA group or the BETA group. You will see screen 5

SCREEN 5 (user interface)

At the top of the screen is your id number. Please record this on your Record Sheet. Below this the screen informs you which group you are in and how many members there are in each group. In this practice session, the ALPHA group has 4 members and the BETA group has 5 members. Next on the screen is a table, describing how your earnings depend on your choice of either $\mathrm{X}$ or $\mathrm{Y}$ and on which group has the most members choosing $\mathrm{X}$. The display in front of the room shows you what the screen looks like for a member of the Alpha group. It also tells you what your $\mathrm{Y}$ bonus is. We will explain what this means in a moment.

You will choose either $\mathrm{X}$ and $\mathrm{Y}$ by highlighting the corresponding row label and clicking with your mouse.

SCREEN 6x and 6y and 7 (showing highlighting)

Your earnings are computed in the following way. It is very important that you understand this, so please listen carefully. Suppose you choose $X$. If your group has more members choosing $X$ than the other group, then you will earn 105 points; if both groups have the same number of members choosing $\mathrm{X}$, then you will earn 55 points, and if the other group has more members choosing $X$ than your group, then you will earn 5 points. 
Alternatively, suppose you choose Y. If your group has more members choosing $X$ than the other group, then you will earn 105 points plus your $\mathrm{Y}$ bonus; if both groups have the same number of members choosing $\mathrm{X}$, then you will earn 55 points plus your Y bonus, and if the other group has more members choosing $X$ than your group, then you will earn 5 points plus your Y bonus. The amount of your Y-bonus is assigned randomly by the computer and is shown in the fourth line down from the top of your screen. In any given round you have an equal chance of being assigned any Y-bonus between 0 and 55 points. Your Y-bonus in each round does not depend on your Y-bonus or decisions in previous rounds, or on the Ybonuses and decisions of other participants. Since Y-bonuses are assigned separately for each participant, different participants will typically have different Y-bonuses. While you are told your own Y-bonus, you are never told the Y-bonuses of other participants. You only know that each of the other participants has a Y-bonus that is some number between 0 and 55 .

Here is an example: Suppose that one member of the ALPHA group chose $\mathrm{X}$ and two members of the BETA group choose $\mathrm{X}$. Then the BETA group has more members choosing $X$ than the ALPHA group. Each member of the ALPHA group who chose X earns 5 points; each member of the ALPHA group who chose Yearns 5 points plus his or her own personal Ybonus ; the members of the BETA group who chose $\mathrm{X}$ earn 105 points, and each member of the BETA group who chose Yearns 105 points plus his or her personal Y-bonus.

The bottom of the screen contains a history panel. During the various sessions and rounds, this panel will be updated to reflect the history of your past sessions.

After you and the other participants have all made your choices of $\mathrm{X}$ or $\mathrm{Y}$ the screen will change to highlight the row corresponding to your own choice, and the column of the group which had the greatest number of members choose X.

At the end of each round until the session ends, you will be randomly divided between groups, and will have the opportunity to choose between $\mathrm{X}$ and Y. In other words, you will not necessarily be in the same group during each round. At the end of each session, you will see a screen summarizing the amount that you earned.

SCREEN 8 (match complete)

If you have any questions at this time, please raise your hand and ask your question so that everyone in the room may hear it.

PRACTICE SESSION

[BRING UP PAYMENT SCREEN FOR PRACTICE SESSION]

We will now give you a chance to get used to the computers with a short practice session. Please take your time, and do not press any keys or use 
your mouse until instructed to do so. You will NOT be paid for this session, it is just to allow you to get familiar with the experiment and your computers.

If your ID number is even, please highlight the Y row and click; if your ID number is odd, please highlight the $\mathrm{X}$ row and click. Once everyone has made their selection, the results from this first practice round are displayed on your screen.

Remember, you are not paid for this practice round.

We will now proceed to the second practice round. Notice that you may have been reassigned to a new group, since the group assignments are shuffled randomly between each round. Please make the opposite choice from the choice you made in the first practice round. That is, if your ID number is even, please highlight the $\mathrm{X}$ row label and click; if your ID number is odd, please highlight the Y row label and click. Once everyone has made their selection, the results from this second practice round are displayed on your screen.

Since this is the end of the practice round, your total earnings for this practice session are displayed on your screen in points (though of course, you wont actually receive that money). We have now completed the practice session.

[QUIZ]

You will notice that a quiz has popped up on your screen. Please read each question carefully and check the correct answer. Once everyone has answered the questions correctly, you may all go on to the second stage of the quiz. After successfully completing the second round of questions, we will commence with the first paid session. If you have difficulty with the quiz or have other questions please your hand.

[END QUIZ]

The first paid session will follow the same rules as the practice session. Let me summarize those rules before we start. Please listen carefully. In each round of this session, 4 players will be randomly assigned to the Alpha Group and 5 players will be assigned to the Beta Group. You may choose $\mathrm{X}$ or $\mathrm{Y}$. As you can see on the table of this screen, if you choose $\mathrm{X}$, your payoff will be 105 POINTS if your group has more members choosing $\mathrm{X}$ than the other group, 5 POINTS if your group has fewer members choosing $\mathrm{X}$, and 55 POINTS if it is a tie. If you choose $\mathrm{Y}$, you will also receive the Y-bonus shown on your screen..

There will be 50 rounds in this session. After each round, group assignments will be randomly reshuffled. Therefore, in some rounds you will be in the Alpha group and in other rounds you will be in the Beta group. In either case, everyone is told which group they are in before making a choice of $\mathrm{X}$ or $\mathrm{Y}$. 
Are there any questions before we begin the first paid session [Answer questions.]

Please pull out your dividers.

SESSION 1

We will now begin with session 1. Do not click anything else on the screen until you are told to do so.

[BRING UP PAYMENT SCREEN FOR SESSION 1]

Please begin.

(Play rounds 150 )

Session 1 is now over. Please record your total payoffs for this session on your record sheet.

[WAIT FOR STAFF TO VERIFY PARTICIPANTS RECORD SHEET] SESSION 2

We will now begin session 2.

[BRING UP PAYMENT SCREEN FOR SESSION 2]

The second paid session will be slightly different from the first session. Let me summarize those rules before we start. Please listen carefully. In each round of this session, 3 players will be randomly assigned to the Alpha Group and 6 players will be assigned to the Beta Group. You may choose $\mathrm{X}$ or $\mathrm{Y}$. As you can see on the table of this screen, if you choose $\mathrm{X}$, your payoff will be 105 POINTS if your group has more members choosing $\mathrm{X}$ than the other group, 5 POINTS if your group has fewer members choosing $\mathrm{X}$, and 55 POINTS if it is a tie. If you choose $\mathrm{Y}$ you will also receive the Y-bonus shown on your screen..

There will be 50 rounds in this session. After each round, group assignments will be randomly reshuffled. Therefore, some rounds you will be in the Alpha group and other rounds you will be in the Beta group. In either case, everyone is told which group they are in before making a choice of $\mathrm{X}$ or $\mathrm{Y}$.

Are there any questions before we begin the second paid session?

Please Begin.

(Play rounds 1-50)

Session 2 is now over. Please record your total payoffs for this session on your record sheet. 